University of Nebraska - Lincoln

DigitalCommons@University of Nebraska - Lincoln

Faculty Papers and Publications in Animal

Science

Animal Science Department

$11-1-1990$

\title{
Alternative methods of selection for litter size in mice: I. Characterization of base population and development of methods
}

\author{
A. C. Clutter \\ University of Nebraska-Lincoln, aclutter2@unl.edu \\ Merlyn K. Nielsen \\ University of Nebraska-Lincoln, mnielsen1@unl.edu \\ R. K. Johnson \\ University of Nebraska-Lincoln, rjohnson5@unl.edu
}

Follow this and additional works at: https://digitalcommons.unl.edu/animalscifacpub

Part of the Animal Sciences Commons

Clutter, A. C.; Nielsen, Merlyn K.; and Johnson, R. K., "Alternative methods of selection for litter size in mice: I. Characterization of base population and development of methods" (1990). Faculty Papers and Publications in Animal Science. 88.

https://digitalcommons.unl.edu/animalscifacpub/88

This Article is brought to you for free and open access by the Animal Science Department at DigitalCommons@University of Nebraska - Lincoln. It has been accepted for inclusion in Faculty Papers and Publications in Animal Science by an authorized administrator of DigitalCommons@University of Nebraska - Lincoln. 
Published in Journal of Animal Science, Vol 68, Issue 11 (1990), pp. 3536-3542. Copyright (C) 1990 by American Society of Animal Science. Used by permission.

\title{
Alternative methods of selection for litter size in mice: I. Characterization of base population and development of methods
}

\author{
A. C. Clutter, M. K. Nielsen and R. K. Johnson \\ University of Nebraska-Lincoln 68583-0908.
}

Studies on a base population of mice were used to establish an index of components of litter size and a physiological model for measuring uterine capacity to be used subsequently in a selection experiment evaluating alternative methods for practicing selection to increase litter size. Heritability estimates of litter size, ovulation rate and ova success (fraction of ova resulting in fully formed pups) were $.18, .33$ and .15 , respectively. No significant genetic or phenotypic correlation was found between overall ovulation rate and ova success. Phenotypic means and genetic variances were higher for characteristics measured on the right than on the left side of the reproductive tract. Linear and quadratic selection indexes, derived for a quadratic definition of breeding value, were compared. The linear index was predicted to be .99 as efficient as the quadratic one. Due to simplicity, the linear index $(\mathrm{I}=1.21 \mathrm{x}$ ovulation rate $+9.05 \mathrm{x}$ ova success $)$, scaled to have variance the same as litter size, was chosen for use. Ovulation rate in unilaterally ovariectomized females was .95 of that in females with both ovaries. No hypertrophy of the ipsilateral uterine horn in unilaterally ovariectomized females was found before implantation of embryos. Thus, unilateral ovariectomy appears to provide a physiological state to measure uterine capacity (as litter size) in the mouse. 


\title{
ALTERNATIVE METHODS OF SELECTION FOR LITTER SIZE IN MICE: I. CHARACTERIZATION OF BASE POPULATION AND DEVELOPMENT OF METHODS 1
}

\author{
A. C. Clutter ${ }^{2}$, M. K. Nielsen ${ }^{3}$ and R. K. Johnson ${ }^{3}$ \\ University of Nebraska-Lincoln 68583-0908
}

\begin{abstract}
Studies on a base population of mice were used to establish an index of components of litter size and a physiological model for measuring uterine capacity to be used subsequently in a selection experiment evaluating altemative methods for practicing selection to increase litter size. Heritability estimates of litter size, ovulation rate and ova success (fraction of ova resulting in fully formed pups) were $.18, .33$ and .15 , respectively. No significant genetic or phenotypic correlation was found between overall ovulation rate and ova success. Phenotypic means and genetic variances were higher for characteristics measured on the right than on the left side of the reproductive tract. Linear and quadratic selection indexes, derived for a quadratic definition of breeding value, were compared. The linear index was predicted to be .99 as efficient as the quadratic one. Due to simplicity, the linear index $(I=1.21 \times$ ovulation rate $+9.05 \times$ ova success $)$, scaled to have variance the same as litter size, was chosen for use. Ovulation rate in unilaterally ovariectomized females was .95 of that in females with both ovaries. No hypertrophy of the ipsilateral uterine hom in unilaterally ovariectomized females was found before implantation of embryos. Thus, unilateral ovariectomy appears to provide a physiological state to measure uterine capacity (as litter size) in the mouse.

(Key Words: Mice, Litter Size, Ovulation, Embryo Mortality, Uterus, Selection.)
\end{abstract}

J. Anim. Sci. 1990. $68: 3536-3542$

Introduction

Mice have been used as a model for studying reproduction of litter-bearing species. Because litter size is a relatively complex trait, determined by ovulation rate and the proportion of ova resulting in offspring at term or, alternatively, by the number of potentially viable embryos and the capacity of the uterus (Bennett and Leymaster, 1989), correlated and

\footnotetext{
1 Published as Paper No. 9048, Journal Series, Nebraska Agric, Res. Div., Lincoln. Appreciation is expressed to Jeryl Hauptman for management of animals and aid in collection of data. Reprint requests should be addressed to $\mathbf{M}$. $\mathbf{K}$. Nielsen.

2Present address: Anim. Sci. Dept., Oklahoma State Univ., Stillwater 74078 .

${ }^{3}$ Anim. Sci. Dept.

Received October 10, 1989.

Accepted April 9, 1990.
}

direct effects of selection on its components are of interest. Bradford (1979) reported that in mice, direct selection for embryo survival (litter size + ovulation number) weighted by the size of the litter resulted in a substantial increase in both embryo survival number and litter size; selection for ovulation rate gave a large direct response, but no increase in litter size. Johnson et al. (1984) suggested using a selection index of the components of litter size in swine to increase ovulation rate as rapidly as possible without being negated by a decrease in embryo survival; this index gives a different weighting to components than does the natural index of litter size. Christenson et al. (1987) evaluated unilateral ovariectomyhysterectomy in the pig as a biological model allowing expression of variation in uterine capacity independent of variation in ovulation rate. Huang et al. (1987) have examined the effect of altering uterine size at $30 \mathrm{~d}$ of gestation in pigs. 
The present study was undertaken to evaluate alternative methods of selection for increased litter size in mice. Selection on an index of components in the manner proposed by Johnson et al. (1984) and selection on litter size in unilaterally ovariectomized females, intended to select for uterine capacity (Leymaster et al., 1986), were compared to direct selection on litter size. Included in this paper are results from data collected at the initiation of the study to estimate parameters in the base population and establish procedures for alternative methods of selection.

\section{Experimental Data}

A population of outbred, CF1 mice was used to generate lines for evaluation of the following selection criteria:

IX: Selection on an index of ovulation rate and ova success (total number born/ovulation rate), as suggested by Johnson et al. (1984).

UT: Selection on number bom in females that underwent unilateral ovariectomy at $4 \mathrm{wk}$ of age. This was intended as a model for selection on uterine capacity similar to that in the pig (Leymaster et al., 1986; Bennett and Leymaster, 1989).

LS: Direct selection for total number born. This served as the traditional method of selection for litter size and provided a basis to evaluate the relative effectiveness of the alternative selection methods.

LC: unselected control.

Data for Estimation of Base Population Parameters. As selection lines were being generated in this study, additional pairings of base stock were made to produce full- and half-sib families. Daughters from these families provided data for estimating parameters in the base population. Two sets of data were collected. The first (I) involved 242 females from 43 full-sib families. The second set (II) included 639 females from half- and full-sib families produced by 39 sires and 2.76 dams per sire.

Sib matings were avoided in pairing three to five females per male at approximately $9 \mathrm{wk}$ of age. Females were checked for mating plugs daily; mating dates were recorded. Females were killed at $d 17$ of gestation (based on mating plug date $=\mathrm{d} 0$ ) and the following data were collected: left- and right-side ovulation rate, determined by counting corpora lutea on excised ovaries with the aid of dissection and 10x magnification, and number of fetuses in the left and right uterine horns, as an estimation of number bom. Left- and right-side ova success, defined as number of fetuses on a side divided by ovulation rate on that side, and total ova success, defined as total number of fetuses divided by total ovulation rate, were calculated.

Data for Evaluation of Unilateral Ovariectomy Model. The UT criterion was designed to put primary selection emphasis on the female's uterine capacity for producing viable offspring when ovulation rate is not a limiting factor. Because the duplex uterus of the mouse does not allow transuterine migration, we hypothesized that unilateral ovariectomy and the subsequent compensatory increase in ovulation rate of the remaining ovary would create a situation in which a large number of ova were restricted to just one uterine horn. If number born approaches independence from ovulation rate in surgically altered females, then selection for litter size in these females should emphasize uterine potential or capacity (Leymaster et al., 1986).

A study was designed to determine whether a 5-wk period, from surgery at $4 \mathrm{wk}$ of age to pairing for mating at 9 wk of age, would be adequate time to achieve a significant compensatory increase in the ovulation rate of the remaining ovary without significant changes in uterine size prior to implantation of embryos. Spare litters from initiation of the selection study provided animals for this experiment. Female mice from each of 28 full-sib families were assigned randomly to one of three treatments:

LIN: Females underwent right-side ovariectomy, leaving the left side intact.

RIN: Females underwent left-side ovariectomy, leaving the right side intact.

CTL: Females were left intact, serving as the control.

Unilateral ovariectomies were performed under general anesthesia (inhaled methoxyflurane) at $4 \mathrm{wk}$ of age, $1 \mathrm{wk}$ following weaning. Females from all treatments were paired randomly with males at $9 \mathrm{wk}$ of age in mating cages containing three to five females per male; sib matings were avoided. Females were checked daily for mating plugs; mating dates were recorded. Data were collected at d 3 of gestation so that corpora lutea and uterine size characteristics could be measured before implantation of embryos. Because uterine length 
and weight following implantation are influenced by number of embryos, the effect of surgery on uterine size characteristics, free of implantation effects, was of interest.

The following data were collected via dissection after cervical dislocation: total ovulation rate (corpora lutea) and length and weight of left and right uterine homs. Length of uterine homs was measured intact to the nearest micrometer. After the abdominal cavity of the mouse was opened, the reproductive tract was excised and gently positioned for measurement, taking care to minimize contact with the uterine tissue. Measurement was from near the tip of the uterine hom at the oviduct, to a point on the opposite side of the cervix. Ovaries then were removed at the oviduct and put in distilled water until corpora lutea were counted. Each uterine horn then was removed at the cervix and immediately weighed to the nearest $.1 \mathrm{mg}$. Total number of animals included in analysis of ovulation rate and in analyses of uterine characteristics were 169 and 148, respectively. The difference in numbers of observations arose because some females included in the analysis of total ovulation rate were excluded from analyses of uterine size due to signs of implantation of embryos. The timetable for surgery and mating mimicked that designed for use in the UT criterion of the selection study.

\section{Methods of Statlstical Analyses}

Estimation of Base Population Parameters. Data collected at the initiation of the selection study for estimation of population parameters were analyzed in two sets. Left-side, right-side, and total fetuses, ovulation rate and ova success from data set I were analyzed using a model that included the random effect of fullsib family. Analyses of variance and covariance were performed to calculate mean squares and cross-products needed to estimate family variance and covariance components for all traits.

The same variables in data set II were analyzed using a nested model that included random effects of sire and dam nested within sire. Components of variance and covariance were estimated using expected mean squares and cross-products for the nested model. Sire and dam within sire components were combined to give full-sib estimates, which were pooled with full-sib estimates from the analy- sis of data set I. Standard errors for estimates of heritabilities and genetic correlations were approximated using methods described by Falconer (1981). Means, variances and phenotypic correlations also were calculated.

Derivation and Evaluation of the Selection Index. Estimates of parameters were used to derive an index of ovulation rate and ova success to be used as the selection criterion in the IX line. The definition of aggregate breeding value in this case was $M=g_{L S}=$ gTOR $\times \mathrm{g}_{\mathrm{TOS}}$, where $\mathrm{g}_{\mathrm{LS}}=$ breeding value for litter size, $g_{T O R}=$ breeding value for total ovulation rate and $\mathrm{gros}=$ breeding value for total ova success. Wilton et al. (1968) developed the theory for deriving the optimum linear and the optimum quadratic selection criteria when the definition of aggregate breeding value is nonlinear. They showed that the linear index has minimum-squared error among all linear indices, but not among all linear and quadratic indices when net merit is defined to be nonlinear. In their definition of aggregate breeding value, Wilton et al. (1968) used a vector a containing the economic weightings for the component traits and a matrix A containing the economic weightings for the squares and cross-products of the component traits. For $\mathbf{M}=\mathrm{g}_{\mathrm{L} S}$, defined above, $a$ is null and the only non-null portions of $\mathbf{A}$ are those pertaining to the cross-product, gTOR $\times$ gros.

Smith (1967) discussed derivation of the optimum linear selection criterion in the special case in which the definition of net merit is the product of two component traits. The optimum linear selection index of total ovulation rate (TOR) and total ova success (TOS) was derived using parameter estimates from the base population:

$$
\left[\begin{array}{l}
\mathrm{b}_{\mathrm{TOR}} \\
\mathrm{b}_{\mathrm{TOS}}
\end{array}\right]=\mathrm{P}^{-1} \mathrm{G}\left[\begin{array}{l}
\overline{\mathrm{X}}_{\mathrm{TOS}} \\
\overline{\mathrm{X}}_{\mathrm{TOR}}
\end{array}\right]
$$

where $b_{\text {TOR }}$ and $b_{\text {TOS }}$ are the index weightings, $P$ is the phenotypic variance-covariance matrix, $G$ is the genetic variance-covariance matrix and $\overline{\mathrm{X}}_{\text {TOR }}$ and $\overline{\mathrm{X}}_{\mathrm{TOS}}$ are sample means.

The optimum quadratic index of ovulation rate and ova success was derived by obtaining the linear coefficients as shown above, and the matrix of coefficients for the squared $\left(b^{2}\right.$ TOR 
and $b^{2}$ TOS) and cross-product (bTOR,TOS) terms as follows:

$$
\begin{aligned}
& {\left[\begin{array}{ll}
\mathrm{b}^{2} \text { TOR } & \mathrm{b}_{\text {TOR, TOS }} \\
\mathrm{b}_{\text {TOR,TOS }} & \mathrm{b}^{2} \text { TOS }
\end{array}\right]=\mathrm{P}^{-1}} \\
& \mathrm{G}\left[\begin{array}{ll}
0 & 1 / 2 \\
1 / 2 & 0
\end{array}\right] \mathrm{P}^{-1} \mathrm{G}
\end{aligned}
$$

The matrix of 0 and $1 / 2$ values is the A matrix defined in Wilton et al. (1968). The 0 values correspond to no squared terms and the two $1 /$ 2 values sum for the cross-product of $g_{T O R} \times$

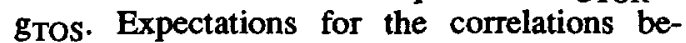
tween aggregate breeding value and each of the indexes were calculated using parameter estimates from the base population. The ratio of these correlations was used to reflect the relative efficiency of the two indexes.

Analysis of the Unilateral Ovariectomy Data. Data from the study designed to evaluate ovarian and uterine compensation for the UT criterion were analyzed using a model including the effects of full-sib family, treatment and family $x$ treatment interaction. Differences between treatment means were tested using the family $x$ treatment interaction as the error term.

\section{Results}

Estimates of Base Population Parameters. Descriptive statistics for the base population are shown in Table 1 along with corresponding acronyms. Ovulation rate, ova success and subsequent number of fetuses (TF) at $\mathrm{d} 17$ were all higher $(P<.01)$ on the right side, whereas variation in each of these traits relative to their mean was slightly greater on the left side. On average, $80 \%$ of the ova shed were represented by fetuses at $d 17$.

Also shown in Table 1 are estimates of heritabilities, genetic correlations and phenotypic correlations for TF, TOR and TOS. The estimated heritability of TOR was slightly more than twice that of TOS. The phenotypic and genetic correlations between TOR and TOS were not significantly different from zero. Phenotypically, TOS varied more closely with TF than did TOR, whereas genetically the opposite was found. Estimates of heritabilities and genetic and phenotypic correlations for left

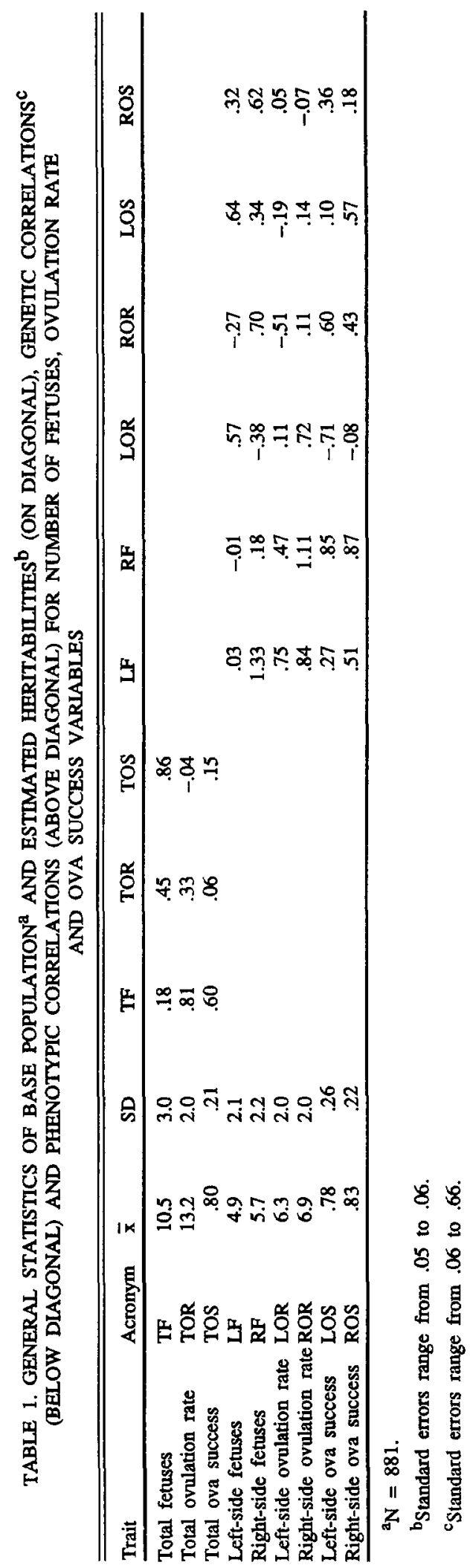


TABLE 2. LEAST SQUARES MEANS FOR TOTAL OVULATION RATE AND UTERINE SIZE CHARACTERISTICS FROM EVALUATION OF UNILATERAL OVARIECTOMY MODEL ${ }^{\mathrm{a}}$

\begin{tabular}{llllll}
\hline \hline Treatment $^{\mathrm{a}}$ & TOR $^{\mathrm{b}}$ & LLNTH, cm & RLNTH, cm & LWT, mg & RWT, mg \\
\hline LIN & 11.72 & 1.91 & 1.65 & 66.2 & 52.4 \\
RIN & 11.42 & 1.56 & 1.75 & 51.7 & 67.0 \\
CTL & 12.13 & 1.94 & 1.86 & 63.5 & 64.9 \\
SE & .24 & .03 & .03 & 1.7 & 1.7 \\
\hline
\end{tabular}

${ }^{a} \mathrm{LIN}=$ left side intact, $R I N=$ right side intact, CTL $=$ control, $T O R=$ total ovulation rate, $L L N T H=$ left-side uterine length, RLNTH = right-side uterine length, LWT = left-side uterine weight, RWT = right-side uterine weight.

b LIN, RIN less than CTL $(P<.09)$.

${ }^{c} \mathrm{CTL}$ greater than RIN $(P<.05)$.

and right sides of the uterus also are presented in Table 1. Estimated heritabilities for number of pups and ova success were greater on the right than on the left side of the uterus. The estimated heritability of ovulation rate was the same for the left and right sides. The phenotypic correlation between LOR and ROR was -.51 , whereas the genetic correlation estimate was positive, .72. Estimates of the genetic correlation between ovulation rate and ova success were -.71 on the left side and .43 on the right. Phenotypic correlations between ovulation rate and ova success were low and negative on both the left and right sides.

Derivation of the Index of Components. Pooled estimates of parameters in Table 1 were used to derive the index for use in the IX line. The optimum linear selection index derived from these parameters was $I=.291 \times$ TOR $+2.19 \times$ TOS. The optimum quadratic index was $\mathrm{I}=.291 \times \mathrm{TOR}+2.19 \times \mathrm{TOS}+$ $.0007 \times \mathrm{TOR}^{2}+.0383 \times \mathrm{TOS}^{2}+.0504 \times$ (TOR $\times$ TOS). Relative selection efficiency of the linear vs the quadratic index was .999. The simpler linear index was chosen as the selection criterion in the IX line. For application, optimum weightings were adjusted so that the index had a standard deviation equal to that of TF (3.0). The resulting index was $I=$ $1.21 \times$ TOR $+9.05 \times$ TOS. The estimated accuracy of $I$, in terms of the expected correlation between the index and breeding value for litter size, was .52.

Unilateral Ovariectomy. In Table 2 are least squares means from the study designed to evaluate unilateral ovariectomy as a model for selection on uterine capacity. Total ovulation rate in LIN and RIN females was significantly less than that of CTL females $(P<.10)$. However, the two unilateral groups tended to approach complete compensation in ovulation rate. Mean ovulation rate of the LIN and RIN groups was about $95 \%$ that of CTL. The LIN group was not different $(P>.40)$ from RIN for number of ovulations.

For uterine size traits, the comparison that reflects the effect of surgery on the remaining uterine horn is that hom with the same side of the control (e.g., comparison of LIN with CTL for left-side length, RIN with CTL for rightside length, etc.). Left-side length, left-side weight and right-side weight of the unilateral group with the corresponding side intact were not significantly different $(P>.30)$ from CTL. However, right-side length was greater $(P<$ $.05)$ for the CTL group than for the RIN group. Importantly, no uterine hypertrophy resulted from ovariectomy.

\section{Discussion}

Mean litter size (10.5) was greater than that reported for mice by Bradford (1979) and Falconer (1971), but less than that in a population studied by Eisen (1978). Bradford (1969) reported a mean proportion of ova resulting in pups at term (.81) similar to that observed in this population, but at a lower mean ovulation rate (10.4). Neal and Johnson (1986) reported a mean embryo survival to d 50 of gestation of .73 and a mean ovulation rate of 14 in a population of swine before initiation of selection to increase litter size.

The heritability estimate for TF (.18) was within the range of those previously obtained for mice using relationships among relatives and realized response to selection. Estimated heritability of TOR for this population (.33) was larger than one based on half-sib correlation in mice (.22; Land and Falconer, 1969) but less than a realized heritability reported in pigs (.42; Cunningham et al., 1979). The similarity between the estimated heritability of TOS (.15) and TF (.18) was somewhat 
surprising, although Bradford (1969) did report response to selection for embryo survival weighted by number born in mice. It should be remembered that ova success, as calculated here, was not adjusted for the number of ova shed.

The absence of a significant phenotypic or genetic correlation between TOR and TOS is in disagreement with results in swine. Neal and Johnson (1986) calculated a genetic correlation of -.30 between ovulation rate in swine and embryo survival to $d 50$, based on offspringparent regression. The lack of a corresponding increase in number born when ovulation rate has been increased through selection in pigs and mice (Zimmerman and Cunningham, 1975; Bradford, 1969, respectively) also indicates a negative relationship. Our full-sib estimates of heritability and genetic correlation may be biased in a positive direction by any variance due to common environmental effects and one-fourth the dominance variance (Falconer, 1981).

Differences between the left and right sides of the female reproductive tract were apparent throughout the analysis of the base population. A larger number of ova shed and a higher ova success rate resulted in a larger number of viable fetuses produced on the right side of the uterus. Estimated heritability on the right versus left side was nearly twice as large for ova success and six times as large for number of fetuses. The phenotypic relationship between ovulation rate and ova success was similar on the two sides, but the estimates of the genetic relationship were vastly different and even favorable on the right side. There also was a negative phenotypic correlation between LOR and ROR. This negative correlation between left and right ovulation rate occurs as a mathematical artifact if binomial sampling (left or right) determines the ovary for each ovulation; the covariance between outcomes in a multinomial, hence binomial, is negative (Freeman, 1987).

The duplex nature of the mouse uterus does not exist naturally in most livestock species. Consequently, number of pups born cannot be accurately determined by total number of ova shed and average ova success, but rather it is the sum of the products of ovulation rate and ova success on the two independent sides. It appears that an interaction between sides, as well as an interaction between ovulation rate and ova success or ovulation rate and uterine capacity within a side, are important in changing litter size through selection in the mouse. Understanding the genetic and physiological mechanisms underlying different aspects of litter size in the mouse is needed to determine to what extent this laboratory species will serve as an adequate model for studying prolificacy in livestock species.

The relative selection efficiency of the linear and quadratic indices revealed no advantage in using a quadratic selection index. Evaluation of how changes in the parameters influence the relative efficiency of the two selection criteria would be of interest. The estimated accuracy of the phenotypic measure of litter size in predicting breeding value in this population can be obtained by taking the square root of the heritability estimate for TF (.18). The estimated accuracy of the index was .52 . The ratio of these two values $\left(.52 /(.18)^{.5}\right)$ indicates a $23 \%$ increase in the expected accuracy of selection for litter size using the linear index versus selection on number born.

Results from the evaluation of unilateral ovariectomy as a biological model for studying uterine capacity were encouraging. For the unilateral ovariectomy procedure to create an appropriate model for this purpose, we think that nearly complete compensation in ovulation rate from the remaining ovary must occur so that phenotypic variation in number born would be primarily due to variation in uterine capacity. A significant effect of the surgery on uterine characteristics prior to the implantation of embryos would hinder the expression of genetic variation in uterine capacity. Removal of either the left or right ovaries at 4 wk of age resulted in an ovulation rate from the remaining ovary at 9 wk that was nearly double that of either ovary in intact females. This compensation took place with no significant increases in either uterine length or weight up to $d 3$ of gestation. Thus, a situation similar to one in the pig described by Christenson et al. (1987) was created in which a relatively large number of ova are restricted to a single uterine horn.

For selection under the UT criterion, excision of the right ovary in all females was chosen as the protocol. Selection is then based on number born in the altered females. The choice of the right side over left, or randomly picking one or the other, was based on the desire to challenge the expression of uterine capacity in the left side, the side exhibiting the lower mean ova success and number of fetuses 
in intact females, even though estimates of heritability for ova success and number of fetuses were higher on the right side.

\section{Implications}

Based on estimates of parameters in the base population, selection on an index of ovulation rate and ova success should be more accurate, and, if selection intensity is not reduced, more responsive than selection on litter size in mice. Unilateral ovariectomy creates a physiological state to measure and practice selection for uterine capacity in the mouse. Selection on these criteria should provide greater understanding of the genetic variation in litter size to aid animal breeders working with livestock species.

\section{Literature Cited}

Bennett, G. L. and K. A. Leymaster. 1989. Interaction of ovulation rate, potential embryonic viability and uterine capacity into a model of litter size in swine. J. Anim. Sci. 67:1230.

Bradford, G. E. 1969. Genetic control of ovulation and embryo survival in mice. I. Response to selection. Genetics 61:905.

Bradford, G. E. 1979. Genetic variation in prenatal survival and litter size. J. Anim. Sci. 49(Suppl. 2):66.

Christenson, R. K., K. A. Leymaster and L. D. Young. 1987. Justification of unilateral hysterectomy-ovariectomy as a model to evaluate uterine capacity in swine. $J$. Anim. Sci. 65:738.
Cunningham, P. J., M. E. England, L. D. Young and D. R. Zimmerman. 1979. Selection for ovulation rate in swine: correlated response in litter size and weight. J. Anim. Sci. 48:509.

Eisen, E. J. 1978. Single-trait and antagonistic index selection for litter size and body weight in mice. Genetics 88:781.

Falconer, D. S. 1971. Improvement of litter size in a strain of mice at a selection limit. Genet. Res. 17:215.

Falconer, D. S. 1981. Introduction to Quantitative Genetics (2nd Ed.). Longman Inc., New York.

Freeman, D. H., Jr. 1987. Applied Categorical Data Analysis. Marcel Dekker Inc., New York.

Huang, Y. T., R. K. Johnson and G. R. Eckardt. 1987. Effect of unilateral hysterectomy and ovariectomy on puberty, uterine size and embryo development in swine. J. Anim. Sci. 65:1298.

Johnson, R. K., D. R. Zimmerman and R. J. Kittok. 1984 Selection for components of reproduction in swine. Livestock Prod. Sci. 11:541.

Land, R. B. and D. S. Falconer. 1969. Genetic studies on ovulation rate in the mouse. Genet. Res. 13:25.

Leymaster, K. A., R. K. Christenson and L. D. Young. 1986. A biological model to measure uterine potential for litter size in swine. Proc. 3rd World Congr. Genet. Appl. Livest. Prod. XI:209.

Neal, S. M. and R. K. Johnson. 1986. Selection for components of litter size in swine: genetic parameters and expected response. Proc. 3rd World Congr. Genet. Appl. Livest. Prod. XI:228.

Smith, C. 1967. A note on the improvement of a trait by selecting on its components. Anim. Prod. 9:127.

Wilton, J. W., D. A. Evans and L. D. Van Vleck. 1968 Selection indices for quadratic models of total merit. Biometrics 24:937.

Zimmerman D. R. and P.J. Cunningham. 1975. Selection for ovulation rate in swine: population, procedures and ovulation response. J. Anim. Sci. 40:61. 